\title{
Comprometimento Organizacional: uma Análise do Conceito Expresso por Servidores Universitários no Cotidiano de Trabalho*
}

\author{
Antonio Virgílio B. Bastos \\ Margarida G. A. Brandão \\ Ana Paula M. Pinho
}

\section{RESUMO}

Os estudos sobre comprometimento organizacional trazem como marca importante a excessiva fragmentação e pulverização de medidas, tornando-se premente a necessidade de análise conceitual que permita estabelecer, de forma mais consensual, os limites do próprio conceito de comprometimento, diferenciando-o de outros construtos usados na pesquisa organizacional. Assim, este estudo objetivou analisar o próprio conceito de comprometimento expresso por trabalhadores, como ponto de partida para se rever os instrumentos padronizados já disponíveis. $\mathrm{O}$ estudo foi conduzido entre servidores de quatro universidades federais (UnB, UFBa, UFMG, UFU); houve, de início, a aplicação de um questionário aberto a 240 servidores; em um segundo momento, entrevistas com uma subamostra de 40 participantes. As respostas foram analisadas qualitativamente, sendo criados distintos sistemas de categorização do conteúdo das informações. Os indicadores levantados permitiram a identificação dos principais focos e bases do conceito de comprometimento expresso pela participantes. Os resultados são confrontados com os conceitos de comprometimento dominantemente utilizados na pesquisa organizacional.

Palavras-chaves: conceito de comprometimento, múltiplos comprometimentos, focos e bases do comprometimento, comprometimento organizacional.

\begin{abstract}
Research on organizational commitment is characterized by an excessive fragmentation and pulverization of measurement. It urges the need for a conceptual analysis that allows the stablishment, in a more consensual manner, of boundaries of the very concept of commitment, by contrasting it with other concepts common to organizational research. Therefore, this study has aimed to analyse the concept of commitment itself, as it is expressed by workers, taking this as a starting point for a revision of the standard instruments currently available. The research was conducted among workers from four public universities (UnB, UFBa, UFMG, UFU). Its first step was the applyance of an open questionnaire to 240 workers, followed by a second phase of interviews with a subsample of 40 workers. Answers were analysed qualitatively, by creating a system of categories for their content. Indicators thus devised have allowed the identification of the main foci and basis of the concept of commitment expressed by the participants. Results are then confronted with the concepts of commitment currently in use in organizational research.
\end{abstract}

Key words: concept of commitment, multiple commitments, foci and basis of commitment, organizational commitment 


\section{INTRODUÇĀO}

No domínio dos estudos sobre comportamento humano nas organizações, a vertente micro do campo Comportamento Organizacional caracteriza-se pela pulverização de conceitos e microteorias que tornam complexa a tarefa de incorporar, em sistemas teóricos crescentemente complexos, as múltiplas contribuições dos trabalhos empíricos que se vêm acumulando, especialmente ao longo das últimas duas décadas.

Tal quadro - em todos os aspectos similar a outros domínios das ciências sociais - pode ser compreendido em termos de duas grandes fontes de tensão interna: a natureza aplicada da área e o seu caráter interdisciplinar. Estudos restritos a contextos organizacionais específicos, prioritariamente voltados para subsidiar políticas de gestão de pessoal e apoiados em tradições de diferentes campos do conhecimento terminam gerando inevitável fragmentação; contribui para tanto o próprio padrão metodológico dominante (Bastos, 1994).

Neste momento, o nosso interesse se volta para a tradição de estudos sobre comprometimento no trabalho e, mais precisamente, para a pesquisa sobre comprometimento organizacional. Entre as diversas possíveis fontes geradoras de fragmentação, nos deteremos sobre a definição do próprio conceito de comprometimento com a organização. Desde o clássico trabalho de Morrow (1983), que aponta a redundância entre múltiplos conceitos de comprometimento, a agenda de pesquisa neste domínio - ainda em proporção insatisfatória - passou a se ocupar de estratégias que minimizassem tal fragmentação.

Uma visão sintética das controvérsias que ainda cercam o conceito de comprometimento organizacional nos é apresentada por Jaros, Jermier, Koehler e Sincich (1993): há discordâncias quanto à sua natureza atitudinal ou comportamental; na vertente atitudinal cresce o consenso de que se trata de um construto multidimensional, embora as pesquisas ainda não sejam conclusivas quanto aos seus componentes nem estabeleçam claramente seus distintos antecedentes e conseqüentes. Há ainda múltiplos conceitos de comprometimento: normativo, 'comprometimento de valor', 'de identificação', afetivo, calculativo, instrumental, moral, 'de continuação'. "Falta de concordância é também evidente no desenvolvimento paralelo de tipologias de comprometimento por vários pesquisadores [...] Assim, a despeito de algum movimento recente em busca de clarificação e consenso, o campo permanece necessitando de um trabalho conceitual integrativo e de estudos empíricos abrangentes"(Jaros et al., p. 953). 
Trata-se de empreendimento indispensável. Os conceitos, por serem classificações saturadas de significados, constituem os blocos de construção da ciência; quando inadequadamente estruturados, podem afetar negativamente todo o empreendimento científico Osigweh (1989). Na realidade, os conceitos e categorias são os blocos de construção do comportamento e pensamento humanos. Embora seja compreensível a existência de múltiplas microteorias explicativas do comprometimento, parece-nos apropriado que os pesquisadores busquem estreitar a sua base de concordância quanto à natureza do próprio fenômeno.

O presente estudo, dando continuidade ao processo de análise conceptual empreendido em trabalho anterior, insere-se na perspectiva de retomar o conceito de comprometimento organizacional partilhado pelos trabalhadores, em toda a sua abrangência e possíveis contradições, fornecendo insumos empíricos para as reflexões sobre os limites das diversas perspectivas conceptuais hoje disponíveis. Mais precisamente, o estudo explora o significado de ser comprometido com a organização, entre servidores de instituições públicas de ensino superior.

\section{O Conceito de Comprometimento Organizacional: Mapeando a SUA Dispersão Na Literatura}

Parcela importante da dispersão de conceitos de comprometimento deve-se à natureza deste tipo de conceito, tanto na nossa linguagem cotidiana, como na linguagem científica, como assinala Bastos (1994). Recorrendo aos procedimentos de análise da linguagem gerados por Ryle $(1949,1979)$, Wittgenstein (1987) e Harzem (1986), o autor explorou o significado do termo comprometimento na lingugem cotidiana e apontou como a sua transposição para o uso científico explica algumas das dificuldades existentes. As conclusões básicas de tal estudo são retomadas a seguir.

No cotidiano, pelo menos três usos do conceito de comprometimento são mais freqüentes: o primeiro aproxima-se dos conceitos de "compromisso", "com envolvimento": descreve formas de como as pessoas se comportam em relação a determinados alvos; "com comprometimento" seria o oposto de "descompromissadamente" e indicaria o grau de atenção, de esforço e cuidado que a pessoa coloca ao realizar algo. Por extensão, comprometimento passou a significar um estado do indivíduo: estado de lealdade a algo, relativamente duradouro, e que pode ser descrito por sentenças que delineiam intenções, sentimentos, desejos. Finalmente, um terceiro uso freqüente refere-se à relação entre conjuntos de condições que conduzem a produtos indesejados: comprometer como prejudicar, impedir. Percebe-se, assim, que o mesmo termo é utilizado para des- 
crever dimensões valorativas opostas - comprometimento como maneiras de agir que podem conduzir a produtos/estados desejáveis, como a falha em atingir tal estado desejado, e comprometimento como tipo de envolvimento que pode dificultar/enviesar as ações da pessoa. Em certo sentido, contudo, os usos de comprometimento trazem em si a noção de "algo que amarra, ata, une" o indivíduo a alguma coisa.

Comprometimento possui, assim, caráter disposicional (não episódico) e adverbial (Ryle, 1949,1979). O seu caráter disposicional fica claro quando se comprometer se reporta a uma propensão a agir, de se comportar de determinada forma. Na realidade, trata-se de conceito disposicional aberto, sendo impossível identificar todas as sentenças que descrevem ações com aquela característica de comprometimento. Ou seja, comportamentos extremamente variados podem ser tomados como realizadores da disposição "estar comprometido com".

Além de disposição aberta, o conceito possui, também, natureza adverbial. $\mathrm{Na}$ linguagem ordinária, são necessárias indicações da maneira ou do modo como as ações são desempenhadas, para que a noção de comprometimento possa ser atribuída adequadamente. Mais especificamente, ações devem possuir características que permitam descrevê-las como comprometidas ou não, o que torna indispensável checar a congruência entre o dizer e o falar. No caráter adverbial do verbo comprometer, se entende que "com comprometimento" não significa uma segunda coisa que foi feita ou algo que existe independente da ação empreendida, mas demanda que algo coerente seja feito para que o comprometimento, como qualidade, possa ser observado.

Na realidade, essa natureza adverbial do conceito de comprometimento não tem sido largamente considerada pelos pesquisadores da área. Predomina, largamente, o tratamento do construto como disposição. Assim o comprometimento é tomado como estado, caracterizado por sentimentos ou reações afetivas positivas, tais como lealdade em relação a algo ao qual se associam intenções comportamentais específicas. No âmbito dos estudos sobre a relação indivíduoorganização, é tratado predominantemente como atitude integrada por dimensões afetiva, cognitiva e comportamental e medido pelos clássicos instrumentos escalares já desenvolvidos nesse domínio do conhecimento.

Como vemos, ao ser utilizado na linguagem científica, o conceito perde sua amplitude, conservando apenas o significado de "engajamento" e eliminando o seu conteúdo de valoração negativa, passando a significar adesão, forte envolvimento do indivíduo com variados aspectos do seu ambiente de trabalho, em especial com a sua organização empregadora. Convivendo com inúmeros outros conceitos (envolvimento, identificação, entre outros), entre as diversas 
definições de comprometimento organizacional, constantes da literatura, pode-se pereceber algumas dimensões de significados comuns, a saber:

. o desejo de permanecer, de continuar; o sentimento de orgulho por pertencer;

. a identificação, o apego, o envolvimento com objetivos e valores;

. engajamento, exercer esforço, empenho em favor de .

Essa perspectiva largamente dominante nos estudos sobre comprometimento organizacional, que parte do instrumento proposto por Porter, Steers, Mowday e Boulian, (1974) e ganha corpo no clássico trabalho de Mowday, Porter e Steers (1982), insere-se nesta vertente atitudinal e toma o fenômeno em perspectiva unidimensional. Os três componentes estariam integrados dentro de modelo atitudinal tripartite; uma medida global de comprometimento é utilizada para predizer vários produtos individuais: desempenho, rotatividade, absenteísmo, por exemplo.

Três grandes dicotomias permitiram que Popper e Lipshitz (1992) sistematizassem os problemas conceptuais associados às definições de comprometimento organizacional disponíveis: (a) a primeira conceitua comprometimento tanto como estado afetivo (identificação com a organização) como em termos de comportamentos pretendidos ou observados (decidir ficar, permanecer na organização); (b) na segunda, ele é conceptualizado em termos de duas manifestações comportamentais diferentes: desejo de atingir ou conservar a adesão como membro da organização (comportamento de continuar ou permanência), e a disposição para exercer esforço extra a seu favor/ interesse (comportamento extra); (c) na terceira, é visto como instrumental, baseado nas expectativas de trocas, perdas e ganhos, e normativo, baseado em valores que ultrapassam as considerações instrumentais.

Crescem, todavia, as evidências de que comprometimento é fenômeno multidimensional. Estudos específicos sobre a dimensionalidade das medidas de comprometimento, associados àqueles que buscaram aprimorar os modelos explicativos de outros fenômenos organizacionais, sobretudo rotatividade, fortaleceram as tentativas de se decompor o conceito, passo inicial para a construção de distintas tipologias de comprometimento organizacional.

Como bem assinalam Yoon, Baker e Ko (1995), no uso cotidiano, o termo comprometimento possui dois componentes: a orientação do indivíduo (a dedicação pessoal) e o aspecto para o qual tal orientação se direciona (a organização). Tal distinção, na literatura tem sido tratada como bases e focos de comprometimento. 
$\mathrm{O}$ afastamento de um conceito atitudinal, global, monolítico e unidimensional se dá em três direções principais, em torno das quais discutiremos os principais desdobramentos das pesquisas, a seguir.

\section{O Próprio Conceito de Organização: a Noção de Múltiplos Focos}

Na realidade, existe uma problematização do próprio conceito de organização. "Está distante de ser claro a que organização, que secção ou nível da organização o conceito se refere, inclusive na prática, quando os dados estão sendo coletados" (Guest, 1992). Quando se está respondendo a uma escala, que representação de organização guia o indivíduo? Ou, mais precisamente, que faceta ou aspecto se torna mais saliente e determina o nível de comprometimento que ele se atribui?

Reichers (1985) parte do pressuposto de que as organizações não são algo monolítico ou entidade indiferenciada que elicia uma identificação por parte do indivíduo. Pelo contrário, elas são constituídas de múltiplos segmentos que nem sempre partilham os mesmos objetivos e valores. Entre esses segmentos destacam-se, por exemplo, a cúpula gerencial, o grupo de trabalhadores, os consumidores ou clientes e os sindicatos. "A organização, para muitos empregados, é uma abstração - uma abstração representada, na realidade, por colegas de trabalho, superiores, subordinados, clientes, e outros grupos e indivíduos que coletivamente integram uma organização" (Reichers, 1985, p.472).

Esse pressuposto traz claras implicações para o estudo do comprometimento organizacional que deveria, a exemplo do que ocorre com os conceitos de satisfação no trabalho e de clima organizacional, ir além de uma medida global, decomposta em comprometimentos específicos. Tal reconceptualização abre a possibilidade de se estudar conflito entre comprometimentos. "Esses comprometimentos refletem um complexo e às vezes problemático apego à organização, que não é evidente na abordagem global [...]" (p.469).

O próprio Reichers (1986) realizou estudo implementando tal diretriz, entre profissionais de organização que presta serviços de saúde mental. Com base em entrevistas identificou quatro 'focos' (segmentos) que se revelaram significativos para a realidade desta organização específica: o topo gerencial, a agência financiadora dos seus programas, os clientes e o público em geral, atendido pelo serviço, e os objetivos e padrões profissionais sustentados pelo grupo de empregados. A medida global de comprometimento organizacional não se correlacionou significativamente com medidas específicas de comprometimento em face de ou- 
tras "facetas" ou "segmentos" da organização, o que, para o autor, fortalece a sua perspectiva de análise deste fenômeno.

Dando continuidade a tal linha de investigação, Gregersen (1993) trabalha com quatro facetas do comprometimento: topo gerencial, supervisores, colegas de trabalho e os clientes, além da medida global de comprometimento organizacional. Diferentes comprometimentos se revelam predizentes de desempenho extrapapel, em faixas diferentes de tempo de serviço na organização.

\section{Os Processos Geradores ou Bases de Comprometimento: Busca de Tipologias de Comprometimento Organizacional}

Partindo-se da crítica de que o conceito global de comprometimento envolveria, simultaneamente, indicadores dos processos que o geram, dos resultados desse estado psicológico passou-se a se preocupar com a definição desse estado: núcleo central ou aspecto substantivo, que define o comprometimento com a organização.

Nessa direção dois principais trabalhos estruturam várias contribuições anteriores, ao proporem a diferenciação de tipos de comprometimento organizacional.

1. O’Reilly e Chatman (1986) destacam que o apego psicológico seria esse núcleo central do construto, o grau em que o individuo interioriza ou adota características ou perspectivas da organização. Tal apego, todavia, poderia ser gerado por diferentes mecanismos que denominou de bases do comprometimento. Apoiados no trabalho de H. Kelman, do final dos anos cinqüenta, sobre mudanças de atitude, os autores discriminam três bases ou processos geradores de comprometimento organizacional: (a) complacência (submissão) ou troca, quando atitudes e comportamentos ocorrem em função de recompensas específicas e não por partilhar crenças, processo que pode levar a diferenças entre atitudes públicas e privadas; (b) identificação ou afiliação: o indivíduo aceita a influência para manter relação satisfatória pelo desejo de afiliação - sentir-se orgulhoso por pertencer, respeitar os valores mas, não necessariamente, assumi-los como seus; (c) internalização, envolvimento que se apóia na identidade entre valores e objetivos pessoais e organizacionais.

Evidências dessa concepção tridimensional do apego psicológico foram encontradas pelos autores em dois estudos em que empregaram análises fatoriais, entre trabalhadores de setor de informática em universidade e entre estudantes de curso de admi- 
nistração. Os autores recomendam a necessidade de aprofundar estudos nesta direção. Em trabalho posterior entre trabalhadores de indústria, Sutton e Harrison (1993) não encontraram suporte para tal modelo tridimensional. Para os autores, duas dimensões foram interpretadas: internalização e identificação integram uma única dimensão, enquanto a complacência se mantém como fator específico.

O estudo de Bar-Hayim e Berman (1992) fortalece tal direção de interpretação, ao analisarem a dimensionalidade da medida de comprometimento organizacional pelas escalas propostas por Porter e colaboradores, e outra, mais reduzida, construida por J. Cook e T. Wall. Os resultados não ofereceram suporte para a estrutura de três dimensões: identificação (aceitação dos valores), envolvimento (desejo de contribuir e se esforçar pela organização) e lealdade (desejo de continuar como membro) que embasou a construção dos referidos instrumentos. Os resultados das análises fatoriais foram mais bem interpretados dentro de estrutura bidimensional. Os autores distinguem o comprometimento passivo (lealdade, desejo de permanecer) do comprometimento ativo (identificação e envolvimento). $\mathrm{O}$ estudo conclui sugerindo que as escalas mais usadas, de caráter aditivo, não fazem distinção importante entre dois padrões distintos de comprometimento com a organização, o que pode explicar os frágeis resultados, quando se toma tal medida global com os antecedentes de rotatividade, de desempenho e absenteísmo etc.

2. O modelo proposto por Meyer e Allen (1991) também se apóia em estrutura tridimensional, referindo-se a três tipos de comprometimento: afetivo, de continuação e normativo.

Cada tipo de comprometimento possui diferentes antecedentes, como explicitado na Figura 1, a partir das idéias apresentadas por Meyer et al. (1993).
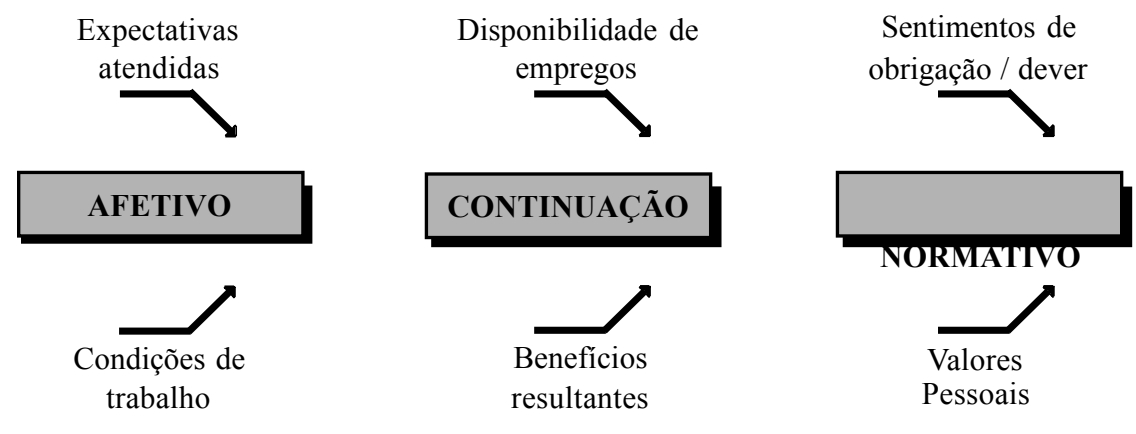

comprometimento afetivo - o apego psicológico mais largamente enfatizado associa-se à idéia de lealdade, sentimento de pertencer, desejo de contribuir e dar energia para a organização, como no clássico trabalho de Mowday e cols. (1982). Envolve ainda sentimento de orgulho e desejo de afiliação (O'Reilly e Chatman, 
1986) ou o prazer em ser membro (Allen e Meyer, 1990). Aqui, não existiria cálculo dos custos e benefícios de continuar na organização; haveria vínculo emocional. Mesmo nos trabalhos que, classicamente, expressam tal enfoque, o comprometimento envolve outras dimensões que não apenas esse vínculo emocional; ele é até menos enfatizado do que o desejo de contribuir, de permanecer, ou a identificação com valores, por exemplo. Jermier e Gaines (apud Jaros et. al., 1993), considerando a pouca ênfase que a dimensão afetiva encontra nas diversas medidas disponíveis, propuseram novo instrumento específico, que a avalia a partir de pares de termos bipolares (ódio-amor; afeição-desprezo; aborrecimento-excitação; raiva-tranquilidade).

comprometimento de continuação - forma de apego psicológico, que reflete o grau em que o indivíduo se sente prisioneiro de um lugar pelos altos custos associados a abandoná- lo. O conceito se apóia na teoria dos side-bets de Becker (1960); é consistente com a teoria da troca ou instrumental - o trabalhador se sente recompensado com o que lhe é oferecido pela organização; a sua saída implicaria sacrifícios significativos: econômicos, sociais, ou psicológicos. Há, aqui, correspondência com o conceito de comprometimento passivo, proposto por Bar-Hayim e Berman (1992).

comprometimento normativo - parte da idéia de internalização ou identificação com valores e objetivos da organização já presente na tipologia proposta por Etzioni (1975). É uma das dimensões principais de todas as medidas de comprometimento. Congruência entre valores (O'Reilly, Chatman e Caldwell, 1991), aceitação dos objetivos e valores (Mayer e Schoorman, 1992) definem esse tipo de comprometimento. "Esta forma de comprometimento difere do comprometimento afetivo porque reflete um sentimento de dever, uma obrigação ou um chamado para trabalhar pela organização, porém não necessariamente um apego emocional". Difere do comprometimento de 'continuação' porque ele não necessariamente oscila em decorrência de cálculos de custos-benefícios" (Jaros et al., 1993, p.955). Como assinalam Angle e Lawson (1993), esse tipo de comprometimento difere significativamente dos demais, mesmo na sua mensuração. Para esses autores, ele parece retratar importante aspecto da propensão ou da inclinaçào em tornar-se comprometido, já que a identificação com os valores organizacionais refletem experiência pessoal e eles são característica do indivíduo, mas do que da relação.

Integrando os desdobramentos das pesquisas sobre focos e bases de comprometimento organizacional, encontramos os trabalhos de Becker (1992) e Becker e Billings (1993). O primeiro desenvolve medidas do grau de apego a quatro focos, segundo sugestão de Reichers (1985): a organização, o topo gerencial, os supervisores imediatos e o grupo de trabalho. Além disso, agrega uma avaliação das 'bases' do comprometimento com esses distintos focos, a partir da medida 
proposta por O'Reilly e Chatman (1986) do grau de internalização, identificação e 'obediência' (cumprimento). Os resultados, segundo o autor, fortalecem a visão multidimensional do construto de comprometimento, ao constatar que a introdução de medidas de comprometimento em face de outros focos e bases explicam a maior porção da variância de medidas da variável dependente (comportamentos prossociais, satisfação e intenção de deixar a organização) do que a medida global de comprometimento organizacional.

Em estudo decorrente, Becker e Billings (1993) investigaram a existência de padrões de comprometimento entre os indivíduos, considerando as 'bases' e 'focos' definidos. Em uma amostra de 440 trabalhadores de uma indústria de suprimentos militares, pela análise de 'cluster', foram identificados quatro padrões de comprometimento com a organização: (a) 'localmente comprometidos' - trabalhadores comprometidos com os seus supervisores e com o grupo de trabalho; (b) 'globalmente comprometidos', com a organização como um todo ou com o topo gerencial; (c) 'comprometidos' - vínculo tanto local como global; e (d) 'descomprometidos' - sem vínculo com quaisquer dos focos. Várias diferenças e similaridades são encontradas nestes quatro grupos, quando são consideradas as bases do compromisso.

Tais trabalhos fortalecem a perspectiva que enfatiza a necessidade de decompor a medida global de comprometimento em medidas mais específicas para identificar padrões ou estruturas de organização desses compromissos e possíveis conflitos entre comprometimentos.

\section{O Dizer-se e o Mostrar-se Comprometido: a Necessidade de Abordagem Comportamental}

Paralelo ao desenvolvimento do enfoque atitudinal existem estudos que configuram uma abordagem comportamental do comprometimento.

O importante trabalho de Becker (1960, p.33), pertinentemente, assinala que o conceito de comprometimento procura explicar "o fato de que os indivíduos se engajam em linhas consistentes de ação [ou o] comportamento consistente [...] que persiste ao longo do tempo". A consistência ao longo do tempo não é a única dimensão importante do comportamento que o conceito procura capturar; envolve também a consistência entre um conjunto diversificado de atividades e a rejeição de alternativas possíveis. Apoiado na crítica de que as principais tentativas de explicação da consistência do comportamento (controle social, internalização de valores, postulação de necessidades) são circulares e tautológicas, o autor 
afirma a necessidade de se especificar "as características do 'estar comprometido' independentemente do comportamento comprometido que servirá para explicar" (Becker, 1960, p.35).

Kiesler e Sakamura (1966) argumentam que o comprometimento é vínculo do indivíduo com atos ou comportamentos, fazendo com que as cognições relativas a tais atos se tornem mais resistentes a mudanças posteriores. Verifica-se o estabelecimento de um círculo de auto-reforçamento, no qual o comportamento leva ao desenvolvimento de atividades que vão, por sua vez, determinar comportamentos futuros, fortalecendo de forma lenta e contínua o crescimento do vínculo comportamental e psicológico do indivíduo com a organização. Assim, conclui Salancik (1977), as pessoas se tornam comprometidas pela implicação das suas próprias ações. Por isso a avaliação do comprometimento não se pode limitar às verbalizações dos indivíduos, mas mediante focalização de manifestações observáveis que vão além das expectativas organizacionais normatizadas. Nesse sentido, poderiam ser considerados como alguns indicadores de comprometimento os seguintes: a assiduidade, a pontualidade, o tempo de serviço e a qualidade adicional no desempenho das tarefas.

A predominância da perspectiva atitudinal faz com que sejam raros estudos que buscam avaliar o comprometimento mediante comportamentos expressos pelos trabalhadores. Um dos raros estudos nessa perspectiva consiste no trabalho de Randall, Fedor e Longenecker (1990), que propõem uma escala de comportamentos que expressem comprometimento, validando-a comparativamente com outras medidas de comprometimento. Mesmo assim, estamos diante de uma escala em que o nível de comprometimento ainda continua sendo auto-atribuido pelo sujeito, não existindo avaliação externa, com base em indicadores comportamentais.

Na verdade, o que se reconhece é que, tanto na vertente atitudinal quanto na comportamental, o nível científico do construto comprometimento não é assegurado sem problemas, dado que enfrenta o desafio de delimitar a sua abrangência, definindo de forma precisa os elementos que devem ser medidos ou observados conjuntamente, para que se possa dizer que a disposição esteja concretamente realizada. Desse conjunto de reflexões acerca do conceito de comprometimento organizacional emerge a necessidade de estudos que retomem o conceito que o próprio trabalhador possui sobre o que significa estar comprometido.

\section{Desenvolvimento do Estudo}

Contrária à orientação extensiva e quantitativa, que marca os estudos sobre comprometimento, a presente investigação em grupo definido de trabalhadores 
do setor público, voltou-se para explorar, em maior profundidade, o conceito de comprometimento com a organização.

O primeiro passo envolveu a elaboração e aplicação de questionário em 240 servidores de quatro universidades: UnB, UFBa, UFMG e UFU, de diferentes unidades (administração central, unidades de ensino e órgãos suplementares) e cargos (dos níveis superior, médio e de apoio). Contendo itens abertos, o questionário levantava: o conceito de comprometimento para o servidor; que características ele associava a colegas comprometidos ou descomprometidos com a universidade; como ele próprio expressava o seu comprometimento e que ações da universidade eram percebidas como facilitando o desenvolvimento do vínculo servidor-instituição. A seguir foram tomados dados pessoais e funcionais.

Realizaram-se, posteriormente, entrevistas semi-estruturadas com 40 servidores, nas próprias unidades de trabalho, entre aqueles que responderam ao questionário, no primeiro momento. Essas entrevistas constaram de questões que aprofundavam a exploração do conceito de comprometimento organizacional. De posse de material essencialmente qualitativo, a análise dos dados envolveu a construção de categorias descritivas que, no segundo momento, foram trabalhadas quantitativamente.

Dois grandes eixos guiaram o processo de análise, tendo como suporte as questões teóricas e conceptuais emergentes na literatura. De início, identificou-se em cada segmento da fala (palavras ou sentenças utilizadas espontaneamente pelos participantes) que aspectos do ambiente - focos - eram escolhidos para expressar a sua noção de trabalhador comprometido. Em seguida, levantaram-se as dimensões básicas que caracterizavam o próprio vínculo de comprometimento - as bases ou conteúdos que expressavam, para o sujeito, a natureza dessa relação do trabalhador com as partes significativas da sua organização.

\section{RESULTADOS: DISSECANDO O CONCEITO DE COMPROMENTIMENTO}

A análise permitiu o levantamento de conjunto amplo de 1.523 asserções, tomadas como indicadores de comprometimento para os servidores universitários. A apresentação e discussão de tais resultados se estruturam naqueles dois eixos básicos em que se procedeu à análise do material coletado, e que refletem as duas principais vertentes de discussão ou questionamento da perspectiva unidimensional do conceito de comprometimento organizacional.: os focos e as bases do comprometimento. 


\section{Os Focos do Comprometimento Organizacional}

Quando diante de uma questão aberta - o que significa ser comprometido com a universidade ? - os entrevistados não tomam apenas a universidade, na sua totalidade, como foco ou alvo de orientação pessoal rotulada de comprometida. $\mathrm{Na}$ realidade, dentre os focos propostos por Reichers (1985), apenas três dominam o seu discurso: o trabalho, a organização e grupo (colegas). O quarto foco toma características pessoais ou estados psicológicos do próprio trabalhador, revelando a extensão em que o conceito de comprometimento é, de fato, um conceito disposicional. Esses resultados vêem-se na Figura 1.

Figura 1: Distribuição de Indicadores por FOCOS de Comprometimento

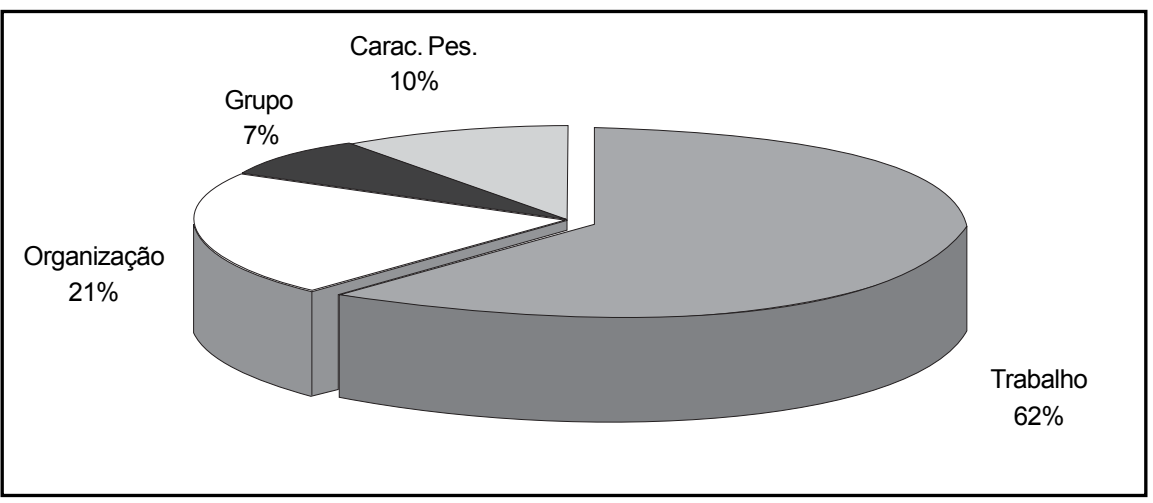

O amplo predomínio de indicadores que tomam o desempenho do próprio trabalho como expressando a disposição de comprometimento organizacional explica a alta correlação que se encontra entre envolvimento com o trabalho e comprometimento organizacional na literatura.

Uma visão mais detalhada do conteúdo dos indicadores que elegeram o trabalho/tarefas como foco se vê na Tabela 1 . O mais freqüente, presente na grande maioria dos participantes do estudo, refere-se ao cumprimento dos deveres e obrigações relativas ao seu posto de trabalho. Em seguida, aparecem indicadores que revelam preocupação com a qualidade dos serviços realizados, produtividade, além de assiduidade e pontualidade. Aspectos como satisfação com a tarefa, organização, disponibilidade e interesse para realizar o trabalho, aparecem menos freqüentemente na fala dos servidores. 


\section{TABELA 1: Indicadores de Comprometimento que tomam o TRABA- LHO como Foco.}

\begin{tabular}{|l|c|c|}
\hline \multicolumn{1}{|c|}{ INDICADORES } & N & \% \\
\hline Cumprir com as obrigações, deveres, desempenhando tarefas & 188 & 20,1 \\
\hline Apresentar um bom desempenho em suas tarefas & 128 & 13,7 \\
\hline Assumir as responsabilidades pelo seu trabalho & 120 & 12,8 \\
\hline Ser pontual no trabalho & 110 & 11,8 \\
\hline Ser assíduo no trabalho & 75 & 8,0 \\
\hline Ser produtivo/ desempenhar as tarefas em tempo hábil & 74 & 7,9 \\
\hline Ser dedicado e engajado no trabalho & 44 & 4,7 \\
\hline $\begin{array}{l}\text { Dar sugestões para melhoria do trabalho e } \\
\text { solução de problemas }\end{array}$ & 42 & 4,5 \\
\hline Dar valor ao trabalho & 40 & 4,3 \\
\hline Ter disponibilidade/interesse para realizar o trabalho & 27 & 2,9 \\
\hline Organizar o trabalho & 25 & 2,7 \\
\hline Fazer o que lhe é solicitado & 25 & 2,7 \\
\hline Ir além das tarefas prescritas & 17 & 1,8 \\
\hline $\begin{array}{l}\text { Desempenhar o trabalho independente } \\
\text { das condições adversas }\end{array}$ & 14 & 1,5 \\
\hline Trabalhar com satisfação & 05 & 0,5 \\
\hline & 934 & 100,0 \\
\hline \multirow{2}{*}{ TOTAL } & & \\
\hline
\end{tabular}

Apenas um pouco mais de $1 / 5$ dos indicadores de comprometimento organizacional tomam a própria organização enquanto foco. Aqui, a noção mais forte, relaciona-se com o cumprimento das normas institucionais e respeito à hierarquia; vêm, a seguir, indicadores de preocupação com o crescimento e desenvolvimento da própria organização. Pode-se observar a discriminação desses indicadores, de forma detalhada, na Tabela 2.

É interessante assinalar que, entre as dimensões utilizadas por Porter et al. (1974) para definir comprometimento organizacional, todas aparecem espontaneamente na fala dos servidores: a idéia de identificação, o desejo de se esforçar 
pela organização são claramente presentes, sob diferentes formulações. Aparece, de forma reduzida, apenas a idéia de permanência ou o desejo de continuar como membro.

Constatou-se, ainda, que certo número de asserções, acerca do que seria comprometimento com a universidade, se referem a comportamentos e atitudes dos indivíduos em face do grupo de trabalho, como podemos ver na Tabela 3. Em síntese, tais indicadores apontam para atitudes positivas perante os colegas, implicando a responsabilidade do indivíduo em construir ambiente de trabalho saudável.

\section{TABELA 2: Indicadores de Comprometimento que Tomam a ORGANIZAÇÃO como Foco.}

\begin{tabular}{|l|l|l|}
\hline \multicolumn{1}{|c|}{ INDICADORES } & N & \multicolumn{1}{|c|}{$\%$} \\
\hline $\begin{array}{l}\text { Respeitar a hierarquia, normas e procedimentos } \\
\text { institucionais/ obedecer a chefia }\end{array}$ & 52 & 15,8 \\
\hline $\begin{array}{l}\text { Visar o progresso da instituição/ preocupação } \\
\text { com o seu crescimento }\end{array}$ & 47 & 14,2 \\
\hline Zelar pelo patrimônio da instituição & 37 & 11,2 \\
\hline Buscar crescer pessoal e profissionalmente junto à instituição & 35 & 10,6 \\
\hline Zelar pela imagem da instituição & 29 & 8,8 \\
\hline Demonstrar amor e gosto pela instituição & 22 & 6,7 \\
\hline Conhecer e preocupar-se com os direitos e deveres & 19 & 5,8 \\
\hline Participar da vida institucional & 15 & 4,5 \\
\hline Buscar melhorias para a instituição & 12 & 3,6 \\
\hline "Vestir a camisa da instituição" & 11 & 3,3 \\
\hline Estar disponível, ser útil à instituição & 10 & 3,0 \\
\hline Ter um contrato de trabalho & 08 & 2,4 \\
\hline Participar da política universitária & 08 & 2,4 \\
\hline Zelar pelo seu setor de trabalho & 06 & 1,8 \\
\hline Permanecer na instituição apesar de outras oportunidades & 05 & 1,5 \\
\hline Outros & 14 & 4.2 \\
\hline & 330 & 100.0 \\
\hline
\end{tabular}




\section{TABELA 3: Indicadores de Comprometimento que Tomam o GRUPO como Foco}

\begin{tabular}{|c|c|c|}
\hline INDICADORES & $\mathbf{N}$ & $\%$ \\
\hline Cooperar com os colegas & 51 & 50,0 \\
\hline Relacionar-se bem com os colegas & 36 & 35,3 \\
\hline Transformar o ambiente de trabalho em local agradável & 08 & 7,8 \\
\hline Outros & 07 & 6,9 \\
\hline TOTAL & 102 & 100,0 \\
\hline
\end{tabular}

Finalmente, existe grupo expressivo de respostas (10\%) que não elegem, explicitamente, aspectos do mundo organizacional externos à pessoa, como facetas importantes da organização que poderiam vir a ser alvos de reação de comprometimento do trabalhador, como se vê na Tabela 4.

TABELA 4: Comprometimento como TRAÇO PESSOAL

\begin{tabular}{|l|c|l|}
\hline \multicolumn{1}{|c|}{ INDICADORES } & N & \multicolumn{1}{c|}{$\%$} \\
\hline Ser motivado, ter iniciativa & 68 & 43,3 \\
\hline Ser honesto & 16 & 10,2 \\
\hline Ter seriedade & 15 & 9,6 \\
\hline Ser competente & 13 & 8,3 \\
\hline Separar problemas pessoais dos profissionais & 09 & 5,7 \\
\hline Ser um funcionário exemplar & 08 & 5,1 \\
\hline Ser criativo & 04 & 2,5 \\
\hline Ter postura crítica & 04 & 2,5 \\
\hline Ter ética profissional & 04 & 2,5 \\
\hline Outros & 16 & 10,2 \\
\hline & 157 & 100,0 \\
\hline
\end{tabular}


Pelo contrário, tais respostas associam comprometimento a características, aspectos pessoais ou atributos do próprio trabalhador. Essa categoria abrange opiniões extremamente variadas como "caráter", "ser honesto", "ser competente", "ser sério", "ser criativo", como indicadores de comprometimento, como se vê na Tabela 4.

\section{As Bases do Comprometimento}

O segundo eixo estruturante da análise consistiu na identificação das diferentes bases de comprometimento. Nesse momento, partiu-se dos próprios indicadores apontados pelos servidores, guiados pela literatura sobre a questão. No primeiro momento, os indicadores foram classificados em comportamentais e atitudinais. Novas categorias foram criadas para descrever a variabilidade encontrada dentre desses dois grande grupos, como se vê a seguir. ${ }^{(1)}$

Dentre os indicadores comportamentais foi possível discriminar:

* indicação de comportamento e ações: indentificar falhas, apontar soluções, fazer propaganda da organização, ser pontual, participar da vida universitária (COMP. A).

* ações associadas à especificação de formas, maneiras como a ação ou o seu produto são considerados 'comprometidos': realizar tarefas com afinco e empenho; realizar bem o trabalho; produzir trabalho de boa qualidade; realizar trabalho dentro dos prazos estabelecidos (COMP. B).

Dentre os indicadores atitudinais foi possível discriminar duas grandes orientações: normativa e afetiva. Na orientação normativa, duas subclases de indicadores foram identificadas:

* internalizacão/identificação (ou não) com normas e valores: conhecer os objetivos, zelar pelos objetivos e interesses da organizacão (NORMAT. A).

* obediência, cumprimento do papel/contrato: cumprir as obrigações e deveres, ser disciplinado, respeitar a hierarquia, ser solícito e cordial com o chefe (NORMAT. B).

A orientação afetiva, também se decompõe em duas subcategorias:

* expressão de sentimento/afetos : ser engajado, demonstrar amor e gosto pela organizacão, considerar a organização a sua própria casa/família (AFET. A). 
* disposições ou tendências para a ação: estar disponível para o crescimento da organização, interessar-se por participar da vida organizacional, ter postura crítica, ser honesto, ter seriedade etc (AFET. B).

A distribuição dos indicadores levantados por essas diversas bases pode ser vista na Figura 2. O primeiro resultado que chama a atenção é o peso alto de indicadores comportamentais (41\%), revelando a importância de ações concretas, observáveis e não apenas verbalizações e disposições dos indivíduos para a avaliação do seu comprometimento. Tal peso contrasta com a pouca atenção dada a essa dimensão do conceito pela tradição de pesquisa, dominantemente atitudinal. Importante também que, ao definirem comportamentos, fica explícita a natureza adverbial do verbo comprometer-se: são comportamentos qualificados, definidos em termos das suas características ou modos de realização (18\% dos indicadores na categoria COMP. B).

Figura 2: Distribuição dos Indicadores por BASES de Comprometimento

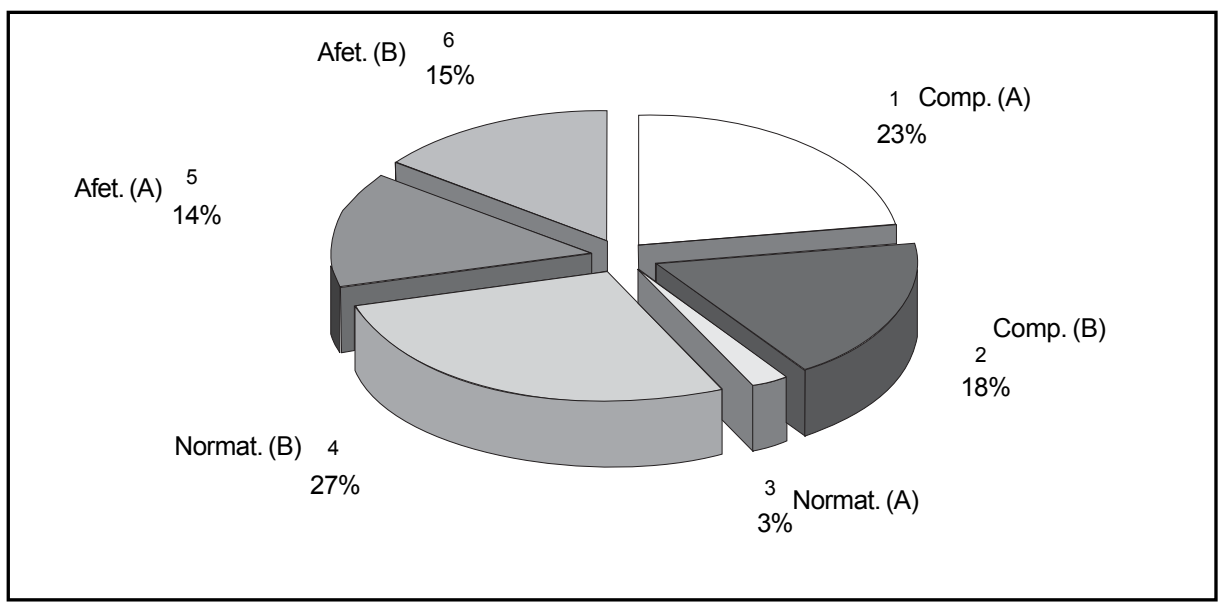

Entre os indicadores atitudinais, observa-se peso equivalente entre os que possuem orientação normativa e afetiva, fortalecendo estas duas bases como as mais importantes para capturar a natureza do vínculo indivíduo-organização, dentre aquelas apontadas por Allen e Meyer (1990) e por O'Reilly e Chatman (1986). $\mathrm{Na}$ realidade, tais bases dão sustentação ao que Bar-Hayim e Berman (1992) chamaram de comprometimento ativo - o indivíduo se identifica com os valores ou com a missão organizacional, ou desenvolve ligação afetiva por encontrar nessta o atendimento de expectativas importantes. Ou seja, a idéia de comprometimento de continuação ou permanência pelos custos associados à saída (o que os autores chamaram de passivo) não entra como núcleo importante da definição, nesse grupo de servidores universitários. 
É certo que o peso da orientação afetiva é ampliado pela inclusão de todas as disposições ou traços pessoais (Afet. B); ele seria bem mais reduzido, se fosse limitado ao conjunto de indicadores que explicitamente avaliam a organização no eixo afetivo (gostar-não gostar). Tais traços ou disposições, contudo, são saturados de dimensão avaliativa positiva, pressupondo trabalhador que tem vínculo afetivo com a organização para a qual trabalha (por exemplo, ser criativo, honesto, ético, exemplar). Aqui, no entanto, observa-se o maior peso do indicador 'ser motivado', mostrando a associação estreita entre motivação e comprometimento, como já constataram pesquisas na área (Mathieu e Zajac, 1990). Na realidade, o conceito de comprometimento possui clara natureza motivacional.

Quanto à orientação normativa, chama atenção o fato do componente internalização/ identificação (Normat A) ter expressão tão reduzida no conjunto de itens, quando é tomado como um dos elementos mais importantes nas escalas de comprometimento organizacional em uso. $\mathrm{O}$ peso dos indicadores que apontam a obediência e respeito à hierarquia (Normat B) mostra a importância de se explorar esse sentimento de dever para com a organização, mesmo porque muitos dos indicadores comportamentais trazem implícita essa noção de cumprimento de dever, do contrato: ser pontual, assiduo, realizar bem as tarefas.

Finalmente, é interessante assinalar, como se vê na Figura 3, que há associação entre o foco escolhido e a base de comprometimento.

Figura 3: Indicadores por FOCOS e BASES de Comprometimento

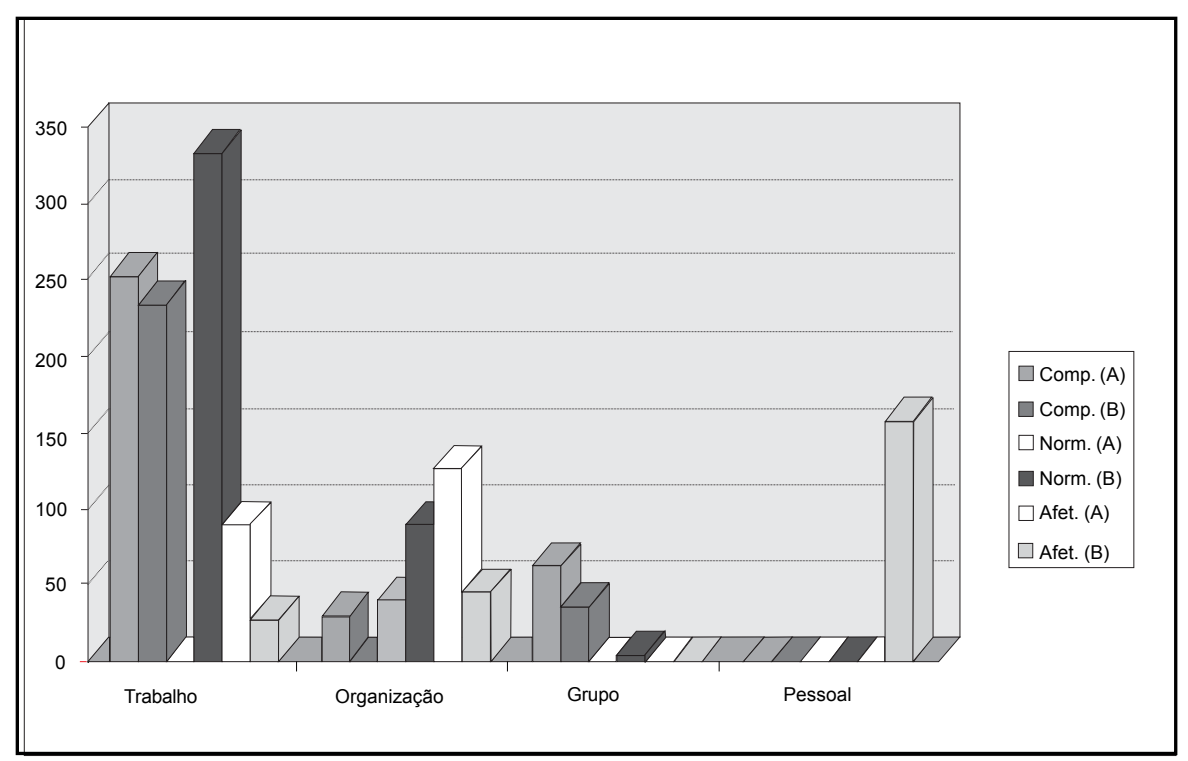


Quando elegem o trabalho como foco, há predominância de indicadores comportamentais, vindo a seguir os indicadores atitudinais normativos que expressam a noção de obediência e cumprimento do dever. Proporcionalmente, são reduzidas as afirmações de relação afetiva com o trabalho como indicador de comprometimento organizacional. Quando o foco é a organização, são raros os indicadores comportamentais. Há largo predomínio de indicadores atitudinais, com eqüilíbrio entre orientação normativa e afetiva. Por outro lado, os indicadores comportamentais dominam amplamente, quando o grupo é tomado como foco do comprometimento.

\section{Considerações Finais}

Os resultados obtidos no estudo, em vários sentidos, parece contribuir para fortalecer uma perspectiva multidimensional ao se estudar o comprometimento organizacional. Todo o movimento na literatura no sentido de romper o conceito monolítico, proposto por Porter et al. (1974) e que se transformou no modelo dominante de investigação na área, parece justificar-se, quer explorando múltiplos focos, quer múltiplas bases.

Neste sentido, a busca de estabelecer padrões de comprometimento, explorando-se a congruência, a complementaridade e possíveis conflitos entre focos e bases constitui alternativa valiosa para os estudos futuros, mostrando que o apego à organização é algo complexo e multifacetado: não se pode limitar a avaliações atitudinais, sendo importante explorar o que se convencionou chamar de abordagem comportamental, muito pouco desenvolvida.

A multiplicidade de noções associadas ao conceito de comprometimento organizacional fortalece o seu entendimento como construto disposicional e, mais concretamente, como disposição aberta, já que são inúmeros os comportamentos levantados como realizadores de tal disposição. Isso, em parte, explica a dispersão de conceitos observada na amostra em estudo.

Não se pode deixar de reconhecer, ainda, que há uma extensão 'indevida' do conceito, quando é associado a múltiplas disposições pessoais. 'Ser comprometido', para o grupo de servidores estudados, partilha espaço semântico com outros conceitos que descrevem atitudes pessoais positivas, o que não significa que tais conceitos possam ser unificados, tanto na linguagem cotidiana quanto na científica.

Duas outras conclusões permitidas pelos dados são importantes. A primeira refere-se à impossibilidade de se considerar comprometimento apenas como atitude. A quantidade de indicadores comportamentais fortalece a recomendação de 
Mowday et al. (1982) de que a vertente comportamental precisa ser incrementada e de que os estudos baseados apenas em medidas atitudinais são insuficientes. Comportamentos e disposições atitudinais são partes integrantes e integradas do conceito de comprometimento no cotidiano dos servidores estudados.

A segunda refere-se à possibilidade de múltiplos processos geradores de comprometimento. Aqui, novamente, encontramos respaldo para dois grandes eixos na definição do próprio conceito: normativo e afetivo. Na realidade, dentro do eixo normativo talvez seja pertinente a distinção entre a internalização/identificação com os valores e com a missão organizacional e a obediência, a submissão às normas e aos valores. Essa distinção diferencia o enfoque normativo (Weiner 1982) do enfoque sociológico (Halaby 1986).

O que falar do clássico enfoque instrumental ou calculativo, terceiro tipo de comprometimento no modelo de Meyer et al.(1993)? Na realidade, tal noção não aparece nas definições de comprometimento pelo servidor. Ela está fortemente presente, no entanto, quando se pergunta o que a universidade pode fazer para ampliar o comprometimento. Aqui, na sua esmagadora maioria, os servidores se reportam a benefícios tais como promoções, treinamento, remuneração, entre outros. A ótica instrumental, ou a expectativa de troca parece permear a quase totalidade das afirmacões, sobretudo se forem insertas as perspectivas de trocas intrínsecas, tais como realização profissional. Nesse sentido, a idéia de instrumentalidade não deveria integrar a definição de comprometimento (como a idéia de vínculo afetivo X normativo) e, sim, ser utilizada para explorar características do processo de comprometer-se com a organização (que tipo de trocas são associadas a que padrão de comprometimento). Resgatar-se-ia, assim, a perspectiva de integrar os níveis individual e organizacional na análise do fenômeno, como sugerido no clássico trabalho de Etzioni (1975).

Finalizando, análises similares deveriam ser estendidas a diferentes contextos organizacionais, sobretudo fora do setor público, no sentido de se verificar se novos indicadores emergem, ampliando os focos e bases aqui identificados.

\section{NOTAS}

*Os dados apresentados neste trabalho foram obtidos no âmbito de um programa de pesquisa
que envolve equipes de quatro universidades: UnB, UFBa, UFMG e UFU. Os trabalhos foram
coordenados, respectivamente por: Jairo Eduardo Borges Andrade (coordenador geral do pro-
grama), Antonio Virgílio B. Bastos, Lúcio Flávio Renault de Moraes e Sinézio Gomide. O
projeto contou com apoio financeiro do CNPq. Os autores agradecem aos demais pesquisadores
a possibilidade de utilizar o banco de dados construído para efeito deste trabalho.
${ }^{1}$ Os códigos ao final de cada categoria são os rótulos utilizados para identificá-las na Figura 2. 


\section{ReFERÉnCias BiblográficAs}

\section{ALLEN, N. J.,}

MEYER, J. P.

The measurement and antecedents of affective, continuance and normative commitment to the organization. Journal of Occupational Psychology, v.63, p.1-18, 1990.

ANGLE, H. L.,

LAWSON, M. B.

Changes in affective and continuance commitment in times of relocation. Journal of Business Research, v.26, n.1, p.3-16, 1993.

BAR-HAYIM, A., BERMAN, G.

The dimensions of organizational commitment. Journal of Organizational Behavior, v.13 , p.379-387, 1992.

BASTOS, A. V. B.

Comprometimento no trabalho: a estrutura dos vínculos do trabalhador com a organização, a carreira e o sindicato. Brasília, 1994. Tese de Doutorado/Universidade de Brasília.

BECKER, T. E., BILLINGS, R. J.

Profiles of commitment: an empirical test. Journal of Organizational Behavior, v.14, n.2, p.177-190, 1993.

BECKER, H. S.

Notes on the concept of commitment. The American Journal of Sociology, v.66, n.1, p.32-40, 1960.
BECKER, T. E.

Foci and bases of commitment: are they distinctions worth making? Academy of Management Journal, v.35, n.1, p.232-244, 1992.

ETZIONI, A.

A comparative analysis of complex organizations. New York: Free Press, 1975.

GREGERSEN, H. B.

Commitments to a parent company and a local work unit during repatriation.

Personnel

Psychology, v.45, p.29-54, 1993.

GUEST, D. E.

Employee commitment and control. In: HARTLEY, J. F., STEPHENSON, G. M. (eds.). Employment relations: the psychology of influence and control at work. Oxford: Blackwell Publishers, 1992.

HALABY, C. N.

Worker attachment and workplace authority. American Sociological Review, v.51, p.634-649, 1986.

\section{HARZEM, P.}

The language trap and the study of pattern in human action. In: THOMPSOON, T., ZEILER, M. D. (eds.) Analysis and integration of behavioral units. Hillsdade, NJ: Erlbaum, 1986. 
JAROS, S. J.,

JERMIER, J. M.,

KOEHLER, J. W.,

SINCICH, T.

Effects of continuance, affective, and moral commitment on the withdrawal process: an evaluation of eight structural equation models. Academy of Management Journal, v.36, n.5, p.952-995, 1993.

KIESLER, C. A.,

SAKAMURA, J. A.

A test of a model for commitment. Journal of Personality and Social Psychology, v.3, p.349-353, 1996.

MATHIEU, J. E.,

ZAJAC, D. M.

A review and meta-analysis of the antecedents, correlates, and consequences of organizational commitment. Psychological Bulletin, v.108, n.2, p.171-194, 1990.

MAYER, R. C.,

SCHOORMAN, F. D.

Predicting participation and production outcomes through a twodimensional model of organizational commitment. Academy of Management Journal, v.35, n.3, p.671-684, 1992.

MEYER, J. P.,

ALLEN, N. J.,

SMITH, C. A.

Commitment to organizations and occupations: extension and test of a three-component conceptualization. Journal of Applied Psychology, v.78, n.4, p.538-551, 1993.
MORROW, P. C.

Concept redundancy in organizational research: the case of work commitment. Academy of Management Review, v.8, n.3, p.486-500, 1983.

MOWDAY, R. T.,

PORTER, L. W.,

STEERS, R. M.

Employee-organization linkages the psychology of commitment, absenteism, and turnover. New York: Academic Press, 1982.

MOWDAY, R. T.,

STEERS, R. M.,

PORTER, L. W.

The measurement of organizational commitment. Journal of Vocational Psychology, v. 14, p.224-24, 1979.

O’REILLY, C. A. III, CHATMAN, J.

Organizational commitment and psychological attachment: the effects of compliance, identification, and internalization on prosocial behavior. Journal of Applied Psychology, v.71, n3, p.429-499, 1986.

O'REILLY, C. A. III, CHATMAN, J.,

CALDWELL, D.

People and organizational culture: a profile comparison approach to assessing person-organization fit. Academy of Management Journal, v.34, p.487-516, 1991.

OSIGWEH, C. A. B.

Concept fallibility in organizational science. Academy of Management Review, v.14, n.4, p.579-594, 1989. 
POPPER, M.,

LIPSHITZ, R.

"Ask not what your country can do for you": the normative bases of organizational commitment. Journal of Vocational Psychology, v.41, n.1, p.1-12, 1992.

PORTER, L. W.,

STEERS, R. M.,

MOWDAY, R. T.,

BOULIAN, P. V.

Organizational commitment, job satisfaction, and turnover among psychiatric technicians. Journal of Applied Psychology, v.5, p.603609, 1974.

RANDALL, D. M., FEDOR, D. B.,

\section{LONGENECKER, C. O.}

The behavioral expression of organizational commitment. Journal of Vocational Psychology, v.36, p.210-224, 1990.

\section{REICHERS, A. E.}

A review and reconceptualization of organizational commitment. Academy of Management Review, v.10, n.3, p. 465-476, 1985.

\section{RYLE, G.}

The concept of mind. London: Hutchinson \& Company, 1949.On thinking. Totowa, New Jersey: Rowman \& Littlefield, 1979.

\section{SALANCIK, G. R.}

Commitment and the control of organizational behavior and belief. In: STAW, B. M., SALANCIK. G. $R$. (eds.). New directions in organizational behavior. Chicago: St. Clair, 1977.

SUTTON, C. D., HARRISON, A. W.

Validity assessment of compliance, identification and internalization as dimensions of organizational commitment. Educational and Psychological Measurement, v.53, 1993.

\section{WIENER, Y.}

Commitment in organizations: a normative view. Academy of Management Review, v.7, 1982.

\section{WITTGENSTEIN, L.}

Investigações filosóficas. Lisboa: Fundação Calouste Gulbenkian, 1987.

\section{YOON, J.,}

BAKER, M. R., KO, J. W.

Interpersonal attachment and organizational commitment: subgroup hypothesis revisited. Human Relations, v.47, n.3, p.329351, 1994. 